\title{
A novel approach to early sickness absence management: The EASY (Early Access to Support for You) way
}

\author{
Evangelia Demou ${ }^{\mathrm{a}, *}$, Judith Brown ${ }^{\mathrm{a}}$, Kaveh Sanati ${ }^{\mathrm{a}}$, Mark Kennedy ${ }^{\mathrm{b}}$, Keith Murray $^{\mathrm{b}}$ \\ and Ewan B. Macdonald ${ }^{\mathrm{a}}$ \\ ${ }^{\mathrm{a}}$ Healthy Working Lives Group, Institute of Health and Wellbeing, College of Medical, \\ Veterinary and Life Sciences, University of Glasgow, Glasgow, UK \\ ${ }^{\mathrm{b}}$ Salus, Occupational Health, Safety \& Return to Work Services, Hamilton, UK
}

Received 7 March 2014

Accepted 15 February 2015

\begin{abstract}
.
BACKGROUND: Sickness absence (SA) is multi-causal and remains a significant problem for employees, employers and society. This makes it necessary to concurrently manage a particular disabling condition and consider the working environment and employee-employer relationship.

OBJECTIVE: To describe and examine the components of a novel SA management service Early Access to Support for You (EASY) and discuss their potential influence on the intervention.

METHODS: A new sickness absence model, starting from day one of absence, was created called EASY. EASY is planned to support both employees and managers and comprises elements already found to be associated with reduction of SA, such as maintaining regular contact; early biopsychosocial case-management; physiotherapy; mental-health counselling; work modification; phased return-to-work; and health promotion activities.

RESULTS: During the EASY implementation period, the SA rate at a health board reversed its trend of being one of the highest rates in the Scottish National Health Service (NHS) and EASY was considered helpful by both managers and employees.

CONCLUSIONS: This paper describes an innovative occupational health intervention to sickness absence management based on the bio-psychosocial model to provide early intervention, and discusses the pros and cons of applying cognitive behavioural principles at an early stage in sickness-absence events, in order to improve return-to-work outcomes.
\end{abstract}

Keywords: Intervention, return-to-work, sickness absence, sickness absence management, rehabilitation

\section{Introduction}

\subsection{Sickness absence}

Sickness absence (SA) not only leads to lost productivity, but is also a measure of poor health [1].

\footnotetext{
*Address for correspondence: Dr. Evangelia Demou, Institute of Health and Wellbeing, College of Medical, Veterinary and Life Sciences, University of Glasgow, Glasgow G12 8RZ, UK. Tel.: +44 141330 3559; E-mail: evangelia.demou@glasgow.ac.uk.
}

It is a significant problem for employees, employers, the health care system, and society [2-5]. Dame Carol Black's review of the health of the working-age population identified the costs of SA and worklessness associated with working-age ill health to be over $£ 100$ billion per annum in the United Kingdom (UK), equivalent to $7.5 \%$ of the Gross Domestic Product [6]. Specifically, SA costs the economy around $£ 15$ billion a year, and 140 million working days are lost to SA (i.e. $2.2 \%$ of all working time, or 4.9 days for 
each worker per year) [7]. Sickness absence varies by industry, and also between the public and private sectors, with the public sector usually having higher SA for reasons that are thought to be largely cultural and behavioural [8]. Sickness absence is multi-causal, and therefore requires not only management of the condition, but also an understanding of the occupational and cultural factors that can be relevant, such as the working environment, employee/employer relationships, lifestyle, and life events [9-13]. An episode of SA can become the onset of a process that leads to ill-health retirement or health-related job loss and long-term disability. Each year 300,000 people make the transition from being in work to being out of work and receiving health-related benefits and this requires an extra $£ 13$ billion in annual state expenditure [7, 14]. Despite these facts, there is a lack of information concerning the optimal health intervention strategies for employees with a high risk of SA $[1,15]$.

\subsection{Sickness absence interventions}

The National Institute for Health and Care (NICE) guidance on long-term sickness and incapacity considers early intervention as an important factor in the delivery of interventions [16]. Similarly the grey literature consistently recommends early intervention in SA $[8,17,18]$. Although early intervention has been reported as an effective measure in SA management [19], there is inconsistency in the definition of early intervention in different studies, with some studies including interventions focusing on those still in work and at risk of SA and other studies including interventions commencing more than two weeks after the start of a SA event [20-23]. Recent systematic reviews found that multidisciplinary interventions involving employees, health practitioners and employers working together to implement modifications for the absentee were consistently more effective than generic non-tailored interventions targeted at all employees [23, 24]. Hoefsmit et al. (2012) concluded that time-contingent- and activating interventions were most effective in supporting return-to-work (RTW), but the earliest intervention included in the review started two weeks postabsence start [23]. Few "very early" (i.e. starting less than two weeks post-absence start) intervention studies exist to our knowledge [25-27], despite the fact that there are a number of commercially successful companies offering SA management services to employers that involve the employee being seen or telephoned on the first day of absence $[28,29]$.

The systematic review by Palmer et al. [30] concluded that future research on interventions to manage musculoskeletal-related SA should focus on the cost-effectiveness of simple, low-cost interventions. The bio-psychosocial model simultaneously considers the biological, psychological and social determinants that may negatively impact on health and well-being, as well as the links between all three factors [31]. This model has been accepted by the World Health Organisation [31, 32] and has been used in the management of SA behaviour in organisations $[28,33]$. Ritchie, Macdonald et al. undertook a review of SA levels in a Scottish Health Board and identified the importance of having SA data available for analysis to tailor occupational health care to the needs of the population [4].

\subsection{Scottish initiatives in sickness absence management}

In Scotland, there are a number of policy initiatives aimed at improving the health of working-age people [34-37]. The Sickness Absence Management (SAM) project was developed to further evaluate the utility of the software SA Recording Tool (SART) in assisting Small and Medium Enterprises (SMEs) manage SA [37]. The Occupational Health and Safety Extra (OHSxtra) NHS pilot was an intervention designed to help NHS employees who are experiencing ongoing health and welfare problems to get support and treatment that improve return-to-work outcomes or prevent sick leave [34]. The Scottish Government produced the Healthy Working Lives (HWL) policy and established the Scottish Centre for Healthy Working Lives (SCHWLs) [35]. The HWL policy is targeted at the employed population, but the increasing recognition of the need to focus also on the workless population, led to its review and the development of the Health Works policy that requires the NHS to consider employability and return-to-work as part of clinical care [36]. In February 2011 the UK Government commissioned a major review of the SA system to help combat the 140 million days lost to SA every year [7]. The review explored how the current system can be changed to help more people stay in work, how to reduce the overall cost of SA, and the overall balance of these costs between the state and employers [38]. Given the current weak economic climate and public sector constraints it is likely that the review will encourage policy makers 
to introduce innovative approaches to further reduce the burden of SA. The Government's response to the review provides one such example with the proposal of the introduction of a Health and Work Assessment and Advisory Service, due to commence in 2014, providing occupational health assessments, case management, and signposting (i.e. informing employees of available resources and services) to appropriate services for employees off sick more than four weeks [14].

\subsection{Sickness absence and the NHS}

The National Health Service in the UK provides free medical care and is funded through central taxation. In Scotland the NHS consists of fourteen regional NHS Boards (including NHS Lanarkshire (NHSL)) that are responsible for the protection and the improvement of their population's health and for the delivery of frontline healthcare services. Additionally there are seven Special NHS Boards and one public health body that support the regional NHS Boards by providing a range of important specialist and national services. All NHS boards have adopted a standard for recording sickness absence (SA), which was defined as "total number of working hours lost due to sickness absence divided by total number of possible working hours" [39, 40]. This measure of SA for all health boards is independently reported by the Scottish NHS Information Services Division (ISD). The Scottish Government also set a challenging Health Improvement, Efficiency, Access, Treatment (HEAT) target of four per cent sickness absence for NHS Scotland, which was to be achieved by 31 March 2009 [41].

In order to respond to this target, the NHS Lanarkshire Occupational Health and Safety Service (SALUS) was invited to propose additional measures to enable the Board to meet this target. The aim of this methodology paper is to describe an innovative very early SA management approach: the 'Early Access to Support to You' (EASY) service. We will examine the components of the EASY service and discuss their potential influence on the intervention. In order that the EASY service can inform the development of evidence-based early SA models for other parts of the public sector and SMEs, an evaluation is required and is being funded by the Scottish Collaboration for Public Health Research and Policy (SCPHRP) and the Chief Scientist Office (CSO). In this paper we will also discuss the research questions that will be addressed by this on-going evaluation.

\section{Methods}

\subsection{Development and introduction of the EASY service}

In 2007 NHS Lanarkshire (11,000 staff) had the highest level of sickness absence (peaking at 7.35\% in January 2007) of all the mainland health boards in Scotland, despite applying all NHS policies directed at supporting sick employees and reducing sickness absence levels [40]. These policies included a conventional attendance management policy including referral to occupational health for absences over 28 days, training managers in return-to-work interviewing, provision of parental and special leave, open access to counselling and staff physiotherapy, and participation in the healthy working lives award scheme. The Efficiency and Productivity Group estimated that if NHS Scotland permanently reduced staff absence by one per cent, a minimum savings of $£ 16 \mathrm{~m}$ could be achieved [42].

Cabinet minister criticism facilitated the development of an innovative approach in NHS Lanarkshire and a development of the existing service was proposed to provide very early intervention based on the bio-psychosocial model [31], applying cognitive behavioural principles, and utilising evidence based interventions [43-46]. The Occupational Health and Safety service of NHS Lanarkshire had already gained experience in the bio-psychosocial approach rather than the medical model for the successful rehabilitation of the long-term workless in receipt of health-related benefits, by providing the Condition Management Programme (CMP) [16, 47]. The existing occupational health service provision was already supported by a staff physiotherapist and an employee counselling service [48].

A review of the scientific literature identified evidence-based interventions that had been found to be effective in the reduction of SA [45, 46, 49-56], which included the following: maintaining contact with the workplace [45, 46, 55]; early intervention by an occupational physician or nurse $[46,49$, 54, 56]; bio-psychosocial case management utilising cognitive behavioural principles [50, 52-55]; musculoskeletal intervention by a physiotherapist [52, 53]; mental health counselling intervention [50-52]; work modification $[46,52,54,55]$; phased return-towork [54]; and health promotion activities [52, 54, 55]. All of these elements were incorporated into a new model called Early Access to Support for You (EASY) (Fig. 1), with support targeted at both 


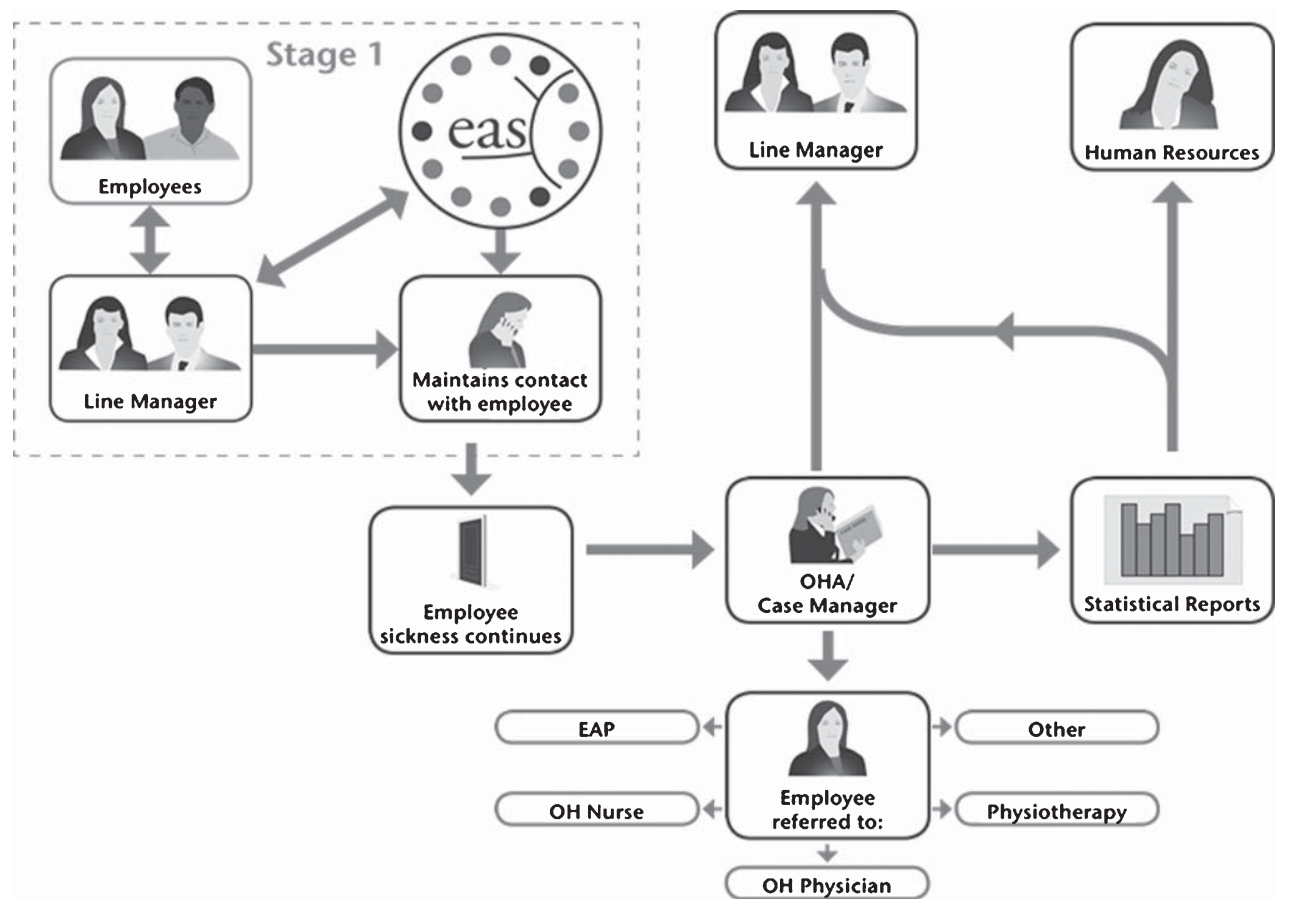

Fig. 1. Schematic of EASY service [47]. The steps include: (i) absentee calls line manager on Day 1; (ii) line manager informs payroll \& EASY; (iii) EASY call handler phones the absentee on Day 1. Offers 'signposting'; (iv) If still absent at Day 3 the EASY call handler phones absentee again and offers sign posting; (v) if still absent at Day 10 absentee referred to $\mathrm{OH}$ and possible referral to a case manager.

employees and managers. Communications between the OHS service, the employee director and management took place with all staff prior to, and throughout, the roll-out of the new service to ensure that all staff were aware of the new service and the changes; had a chance to express their concerns and questions, and it was discussed with all employees what this meant for their working life. Extensive individual and organisation-wide communications were undertaken with all employees, managers and staff representatives prior to the introduction of the service, with the Employee Director being an integral member of the project implementation team. All employees and managers were required to attend briefings and meetings where the new service was being introduced. Communications included articles on the introduction of this new service in the Health Board newspaper and in the local press. Additionally, extensive consultations with local and national (Scottish) trade unions (e.g. STUC) were conducted from the start of the development of the methodology, and during the phased implementation of EASY. Presentations and discussions were held with each department and their different teams. This communication exercise was extensive, comprehensive and repeated with all parts of the organisation to ensure that all staff knew about the new service, and had opportunities to discuss any concerns prior to its introduction to their part of the organisation. Where there were concerns, these were addressed through further consultation, and the service was not introduced into any department until all staff objections or concerns had been satisfactorily addressed.

\subsection{Implementation of the EASY service}

A phased approach to staff enrolment in the EASY service was taken from May 2008 for staff absent from work due to illness, with the aim of enrolling all staff by March 2009. This service was designed to provide a case management approach from the first day of absence. A principle of the service was to remain in contact not only with the employee, but equally with their manager, and to ensure that both were given the maximum support and guidance to help the employee overcome the episode of ill health, and facilitate a supported return-to-work.

The first step to reduce unnecessary or avoidable $\mathrm{SA}$ is to record it accurately for all employees and measure it across different occupational groups [23]. 
The EASY service set up a robust system of reporting and recording SA. For each SA event reported to EASY, consent was obtained for employee participation and use of their anonymised data, and information gathered and recorded by EASY staff (i.e. occupational health) and entered onto a bespoke database and case tracking system that had been developed for the case management service of the CMP programme [47]. This included demographic data and information on job family, division, cause of absence [57], and duration of absence (first day of absence and date of return-to-work).

Human resource (HR) and occupational health $(\mathrm{OH})$ roles were changed from an essentially reactive role to one of proactive support for employees and managers. $\mathrm{HR}$ and $\mathrm{OH}$ advisors were no longer centrally based, but aligned to part of the organisation so that each part of the organisation had its own named HR and $\mathrm{OH}$ health professional, and each manager and employee was supported by a named $\mathrm{OH}$ and HR advisor. This facilitated advice to individuals and their managers, and frequent meetings, e.g. to discuss work adaptations for full, or phased, return-to-work. All the $\mathrm{OH}$ nurses were given additional training in the bio-psychosocial model and case management principles. Funding was obtained for additional HR officers and nurses, to support the roll-out, and to establish the call centre and its staff; to provide additional physiotherapy resource, and improve signposting to other existing services, including staff counselling. The annual cost of this service, including the start-up costs, was $£ 307,570$ [58]. Anonymised analysis of data was provided to divisional and departmental senior managers who were thus made aware of the performance of their part of the organisation and how it compared with other parts of the organisation.

\subsection{Evaluation of the EASY service}

Employees and managers were surveyed to assess their experience of the service. Ethical approval was not required, as this was a service evaluation and participants were NHS staff. Research and Development (R\&D) management approval was granted for the conduct of the employee satisfaction study within NHS Lanarkshire (R\&D ID Number L11071). A satisfaction questionnaire was designed and piloted on 20 NHSL staff. The questionnaire gathered information about which services and signposting staff were offered as part of the EASY intervention, and also the uptake of these services and signposting. Fur- ther it included questions on satisfaction with the EASY call handler and on the overall EASY service. A stratified sample was constructed based on the demographics of NHSL staff and the questionnaire was mailed to 1,000 NHSL staff who had a closed absence between January and April 2012 (therefore respondents included both short term absentees but also longer term absentees from 2011) in June 2012. Reminder letters were mailed out 4 weeks later. If staff had more than one absence they were asked to recall their most recent absence.

\section{Results}

\subsection{The process of the EASY service}

In NHS Lanarkshire, all employees are required to contact their line manager when absent from work due to illness (Fig. 1) and line managers are contractually obliged to inform the Payroll department of an employee's absence on their first day of absence. This core responsibility and relationship was retained by requiring the line manager to report the episode of an absence to the EASY service by telephone or email.

The report of an employee's SA event by their line manager to the EASY service leads to a call to the sick employee by the EASY service by non-clinical call handlers on the same day. This may not necessarily be the first day of absence, but aims to be. Primary compliance - i.e. the percentage of SA events reported to the EASY service that are routinely reported to Payroll - was approximately $74 \%$. Secondary compliance - i.e. the percentage of SA events reported to EASY on the first day of absence - was approximately $80 \%$. Table 1 provides a description of the population that participated in the EASY service by sex, age and job family.

The absent employee is then invited to participate in the programme, and asked if their anonymised data can be used for analytical purposes. If consent is given to participate in EASY, the employee is asked about their health problem causing the sickness absence episode, as well as a series of questions regarding the type of support they may need. Absent employees would be informed about services to which they could self-refer, e.g. occupational health, physiotherapy, counselling service, and also about the Family Friendly leave entitlements and also offered infection control and cold/flu advice, if appropriate. Absentees receive another telephone call on the third day of their absence from the EASY service. If still absent 
at day 10, referral to occupational health (previously happening on day 28) occurs and, dependent on need, assignment to a case manager, who can offer non-clinical support. After each contact, the line manager is contacted and informed about the employee's

Table 1

EASY service population by sex, age and job family (2008-2011)

\begin{tabular}{llrc}
\hline & & Number & \% of total \\
\hline Sex & Male & 3616 & $12.20 \%$ \\
Age & Female & 26033 & $87.80 \%$ \\
& $16-29$ & 4605 & $15.53 \%$ \\
& $30-39$ & 6703 & $22.61 \%$ \\
& $40-49$ & 9558 & $32.24 \%$ \\
& $50-59$ & 7567 & $25.52 \%$ \\
Job Family & $>60$ & 1216 & $4.10 \%$ \\
& Administrative Services & 6053 & $20.42 \%$ \\
& Allied Health Profession & 2903 & $9.79 \%$ \\
& Healthcare Sciences & 1341 & $4.52 \%$ \\
& Manager & 89 & $0.30 \%$ \\
& Medical and Dental & 596 & $2.01 \%$ \\
& Medical and Dental Support & 538 & $1.81 \%$ \\
& Nursing /Midwifery & 13609 & $45.90 \%$ \\
& Other therapeutic & 1176 & $3.97 \%$ \\
& Personal And Social Care & 259 & $0.87 \%$ \\
& Support Services & 3085 & $10.41 \%$ \\
\hline
\end{tabular}

expected progress and return date, and whether any work modifications may be required.

\subsection{Changes of sickness absence rates following the implementation of EASY}

Sickness absence progressively reduced following the phased introduction of the service, which started in April 2008 (Fig. 2). This reduction has continued and NHS Lanarkshire now has one of the lowest SA rates of all health boards in Scotland.

Sickness absence data for NHSL and NHS Scotland excluding NHSL (NHS Rest of Scotland), were requested from NHS Scotland Information Services Division (ISD). The NHSL and NHS Rest of Scotland staff populations remained stable from 2007 to 2012, with the NHSL being on average $7.94 \%$ of the NHS Rest of Scotland staff population (min: 7.82\%; max: 8.01\%). Figure 2 shows SA rates (\%) for NHSL and NHS Rest of Scotland from January 2008 to December 2011. The EASY service was introduced in May 2008, with all staff included by March 2009. Prior to the introduction of the EASY service NHSL had higher SA rates than NHS Rest

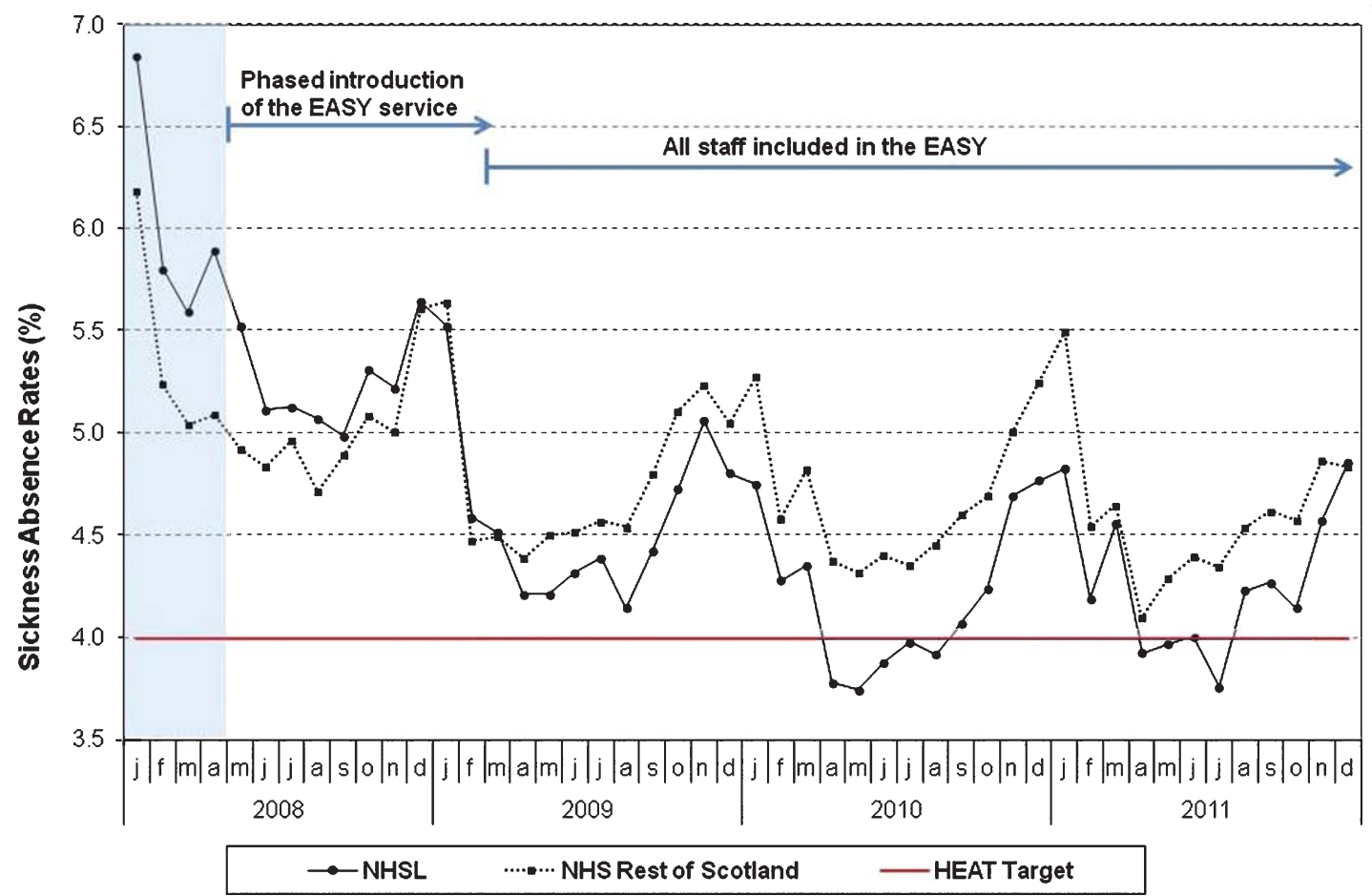

Fig. 2. Trend of SA rate in NHS Lanarkshire and NHS Rest of Scotland (blue shaded area: period pre-introduction of the EASY service)-Data provided by ISD [39]. 
Table 2

Mean duration of sickness absence events by year following the implementation of the EASY service, NHS Lanarkshire

\begin{tabular}{lcc}
\hline Year* & $\begin{array}{c}\text { No of } \\
\text { absences }\end{array}$ & $\begin{array}{c}\text { Mean duration of } \\
\text { absence, days (95\% CIs) }\end{array}$ \\
\hline 1 & 5399 & $16.2(15.2-17.2)$ \\
2 & 9625 & $15.3(14.6-16.1)$ \\
3 & 8857 & $16.0(15.3-16.8)$ \\
4 & 8472 & $12.4(11.9-13.0)$ \\
\hline
\end{tabular}

*Breakdown of Year: 1: May 2008-2009; 2: May 2009-2010; 3 : May 2010-2011; 4: May 2011-April 2012.

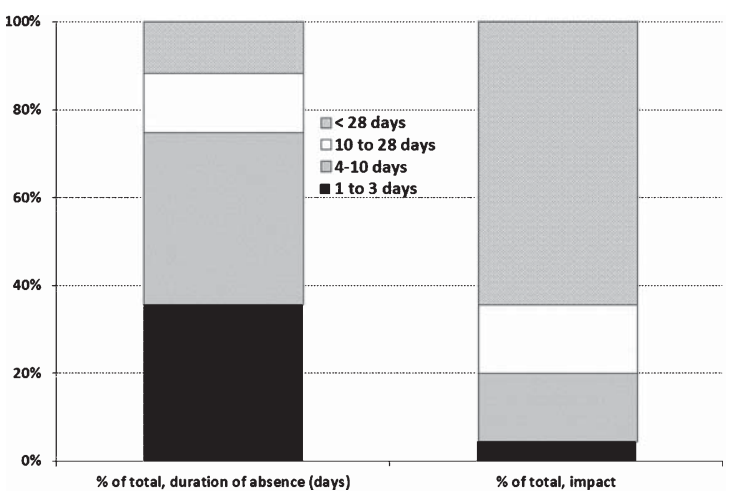

Fig. 3. Duration (days) and impact (days) of sickness absence events as percentage of total SA events.

of Scotland. For example, in January 2008 SA was $6.84 \%$ in NHSL, whereas for NHS Rest of Scotland it was $6.19 \%$. While both NHSL and NHS Rest of Scotland follow a similar declining trend over time, during the EASY service roll-out period (May 2008-March 2009), NHSL SA rates became and remained lower than NHS Rest of Scotland. During two periods, April-August 2010 and April-July 2011, NHSL SA rates achieved a lower SA rate than the 4\% HEAT target (Fig. 2) and reached a low of $3.74 \%$ in May 2010. The sickness absence events are broken down in Fig. 3 by their duration (i.e. how many days a SA event lasted) and their impact (i.e. overall duration, estimated as the product of duration times the number of events within that category). Figure 3 demonstrates that while the vast majority of events $(75 \%)$ only last between one to ten days, the long term absences (i.e. $>28$ days long) account for most of the impact due to their duration. Table 2 demonstrates the duration of SA events following the implementation of the EASY service and shows that from the first to fourth year of the EASY service being introduced, the mean duration of SA events decreased by 3.8 days (Table 2).

\subsection{Staff and managers satisfaction with the EASY service}

From the survey on the evaluation of the EASY service by NHS staff, 257 questionnaires were returned (response rate $25.7 \%$ ). Only $13 \%$ of staff found the initial contact with the call handler unhelpful or very unhelpful ( $42 \%$ found this contact helpful/very helpful; $45 \%$ gave a neutral response). Signposting and/or advice were offered to $49 \%$ of the staff who responded and $57 \%$ of this group took up the signposting and/or advice. The survey responses indicated that the most common advice offered was occupational health $(\mathrm{OH})(44 \%)$, infection control (18\%) and employee counselling services (ECS) (16\%). The more likely signposting/advice staff actually took up was $\mathrm{OH}(70 \%)$ and musculoskeletal services telephone numbers (66\%). Staff were less likely to take up ECS (28\%), cold/flu advice (33.3\%) and infection control advice (31.0\%). Very low numbers were offered health and safety and human resources advice, but did take this advice up. From the staff that had contact with $\mathrm{OH} 81 \%$ found this very helpful/helpful. The help/advice/information received from EASY service was considered very helpful or helpful by $35 \%$ of the respondents ( $51 \%$ gave neutral response; $14 \%$ unhelpful or very unhelpful).

Managers were surveyed separately from the time the EASY service was introduced and for the first three years using SurveyMonkey ${ }^{\circledR}$, to investigate their views and satisfaction with the service. For the 2008-2010 period, a total of 205 responses (74\% average response rate) were received from managers. The managers responses demonstrated that $78 \%$ of the managers found the EASY service useful in helping employees return to work; $60 \%$ expressed that the service made them feel very involved or involved during their employee's absence; and $82 \%$ found the service "useful" in helping managers deal with a SA episode. Overall, $69 \%$ of managers' impressions of EASY were rated as positive or very positive.

\section{Discussion}

\subsection{Impact following the implementation of the EASY service}

This new approach to combat high levels of SA shows that the development and implementation of an evidence-based bio-psychosocial support service for SA appears to have led to a reduction in SA in the 
respective NHS Board. During the implementation period the SA rate of NHS Lanarkshire managed to reverse its trend of being above the Scottish average (NHS Rest of Scotland), to being below the average, and approaching and reaching at times, the $4 \%$ HEAT target. Within one year of this phased introduction, SA had fallen to one of the lowest levels in the Scottish NHS, and these reductions have been sustained and improved. During the same period overtime costs reduced from $£ 3.43 \mathrm{~m}$ in $2008 / 9$, to $£ 2.46 \mathrm{~m}$ in $2009 / 10$ and to $£ 1.85 \mathrm{~m}$ in 2010/11 [58]. The increased availability of staff due to lower SA rates was estimated to being equivalent to having an additional 250 health care workers available for work each day (NHS Lanarkshire Human Resources; personal communication).

If the EASY service was extended across NHS Scotland and reduced Scotland's average SA rate to the NHS Lanarkshire level, there would be a further reduction of sickness absence across Scotland of $0.25 \%$, equivalent to $£ 4 \mathrm{~m}$ savings [42]. Additionally, this figure does not include the reduction in overtime costs, which occurred in NHS Lanarkshire, which if multiplied across Scotland might be as much as $£ 20 \mathrm{~m}$ (as NHS Lanarkshire is approximately $10 \%$ of the Scottish NHS).

\subsection{Components of the EASY service and their role in sickness absence management}

One of the factors contributing to the apparent success of the EASY service could be the creation of a bespoke database, proper recording and followup of sickness absence events. The proper reporting and recording of SA events led to measurements of whom, how many, when, and why people were absent, and this consequently assisted in the strategic development of supportive services. A recent systematic review showed that interventions involving employees, health practitioners and employers working together to implement modifications for the absentee were consistently more effective than other generic and non-multidisciplinary interventions [23, 24]. The criterion for the above review was sickness absence of over two working weeks at the time of intervention. There appears to be a lack of published evidence on very early interventions (i.e. less than two weeks), such as EASY. However, the EASY service integrates, supports and promotes interdisciplinary cooperation between a number of professionals in health care and facilitates contact with the employer during SA, all of which have been described as significant factors for return-to-work $[23,59]$.

This project has also been associated with high satisfaction levels with the service and an increase in the perception that the Lanarkshire Health Board was a good employer [60]. Both employees and managers have positive views of the service. Further analysis of the impact and effectiveness of this early intervention programme in a systematic fashion may provide more detail on the factors that influence a successful sickness absence intervention. The results of this intervention support the use of the biopsychosocial model in this generic and non-condition specific fashion and very early intervention in sickness absence reduction. Hoefsmit et al. (2012) in their review, reported that in many cases interventions are focused on isolated conditions or specific groups of people, making the generalizability of the results or the adaptation of "successful" interventions in other workplaces and for multiple target populations difficult [23].

Despite clear indication of the potential benefits of very early intervention based on the EASY Service, a formal evaluation of the effectiveness and cost effectiveness of this approach is needed before policy makers adopt such an approach throughout Scotland. What is required for the health service, government, and employers to accept and implement such initiatives, is scientifically proven information (e.g. conducting a randomised-control trial) on whether this service improves communications between employees, employers and care providers; and facilitates a faster and sustainable RTW; and if it is cost-effective [15, 61].

In the Department for Work and Pensions Report Building the Case for Wellness it was noted by the authors that a key reason for employers being slow to take up programmes such as sickness management interventions was the lack of robust financial evaluations [62]. The authors suggested this reflected a perception from employers that the required data are difficult to collate, the process is complicated, whilst the benefits cannot be disentangled from other factors affecting workplace performance [62]; whereas, the implementation and delivery of the EASY service has shown that data were straightforward to collect, there was high satisfaction with the service and a reduction in sickness absence and associated costs was achievable.

"Early" sickness absence interventions that facilitate return-to-work and decrease repeat SA events have been documented for absences of two to six 
weeks [23, 24, 63]. Similarly multidisciplinary interventions, which include an array of disciplines, such as physiotherapists, employers, case managers, occupational therapists, ergonomists, occupational physicians, and case workers maintaining contact with the workplace, are also effective in return-to-work for both physical and psychological conditions [23]. The review by Hoefsmit et al. (2012) also assessed "time contingent interventions" and "specific" and "generic interventions" (i.e. interventions targeted at workers with specific diagnoses and interventions irrespective of a specific diagnosis, respectively). The evidence for the effectiveness of the former is inconsistent; whereas, the evidence for the effectiveness of the latter showed no significant effect [23].

The EASY service is a combination of the above, namely time contingent and generic. Data from the Information Services Division Scotland (ISD) depict an "apparent effectiveness" when compared with the rest of Scotland (Fig. 2). High quality research into the characteristics of the programme that influence outcomes the most, as well as the characteristics of employees and conditions at highest risk of sickness absence, can provide the necessary information to assist employers and occupational health professionals to move towards targeted preventive measures to sustain work ability $[1,64]$. Being able to predict which employees are at a higher risk of sickness absence could be very useful for SA intervention models. This preventive rather than reactive approach could be implemented to enhance models such as the EASY service, with the use of questionnaires and surveys to employees. For instance, Taimela et al. (2008) were able to detect individuals with a high or intermediate risk of sickness absence by using a survey to distinguish those with an array of self-assessed problems (e.g. working ability, pain, impairment due to musculoskeletal problems, sleeping problems, fatigue, depression) for their evaluation of an occupational health intervention [1]. Wilford et al. (2008) identified the questions that should be asked to predict a risk of subsequent job loss [65].

\subsection{Future research requirements in sickness absence interventions}

Current knowledge on interventions and intervention characteristics that facilitate a faster recovery and reinstate functional capacity to enable returnto-work following a sickness absence episode is highly relevant to the government, health services, employers and employees. Awareness and insight of cost-effective interventions can lead to optimal and suitable health improvement for employees and reductions in productivity losses for employers. Health and social security policy makers and practitioners can use this knowledge to design evidence-based care that supports employee health and participation in the workforce [23]. Effective interventions for sickness absence can lead to reductions in future care consumption, cost, and dependence on benefits [23]. Previous research has reported that economic evaluations of workplacebased interventions are weak and that is information that is missing in the occupational health and safety (OHS) literature [66]. This makes it essential that interventions such as the EASY service are evaluated in a scientific and robust manner. The aim of this paper was to describe the EASY service, examine the components, and discuss the potential influence of the components of the intervention on return-to-work outcomes. A detailed evaluation of the EASY service has been conducted [58]. This evaluation seeks to answer whether the EASY service reduced sickness absence and whether it was cost-effective; and to explore how the service can be improved and developed into a widely applicable early SA intervention $[58,67]$.

\section{Conclusion}

We describe a very early bio-psychosocial occupational health intervention for sickness absence, which was developed in response to an operational problem in a Scottish Health Board employing around 11,000 health care staff in mainly hospital and community settings. Sickness absence is a major problem for health services and all employers, as well as for the individuals who take time off work. The shortcomings of the traditional model for sickness absence control facilitated an innovative approach that led to a reduction in sickness absence, improved the availability of staff for patient care and was a cost saving intervention.

This paper, describing the methodology of this new occupational health intervention, provides early evidence to support the general but often poorly evidenced consensus [25-27] that early intervention is important, and that the bio-psychosocial model of health is effective [47, 51-55].

Further analysis of data will identify which and if any medical conditions - e.g. musculoskeletal, mental health - are more or less amenable to this 
approach. It will also explore which aspects of the bio-psychosocial intervention are useful in which settings, circumstances, conditions and occupational groups.

\section{Acknowledgments}

The authors would like to acknowledge Joyce Craig, Moyra Anderson and Robert Atkinson for their support in this project and ISD for providing the sickness absence rate data for Scotland. E.B. Macdonald proposed the EASY model; M. Kennedy was responsible for the development of the telephone hub and the IT infrastructure; and K. Murray developed the analytical database. E.D. was funded by the Lanarkshire Acute Hospitals NHS Trust. J.B.was funded by a grant from the Scottish Collaboration for Public Health Research Policy (SCPH/15).

\section{References}

[1] Vahtera J, Kivimaeki M. Reducing sickness absence in occupational settings. Occup Environ Med 2008;65(4):219-20.

[2] Alexanderson K, Norlund A. Swedish council on technology assessment in health care (SBU). Chapter 12 . Future need for research. Scand J Public Health (Suppl) 2004;63:256-8.

[3] Henderson M, Glozier N, Elliott KH. Long term sickness absence - Is caused by common conditions and needs managing. BMJ 2005;330(7495):802-3.

[4] Ritchie KA, Macdonald EB, Gilmour WH, Murray KJ. Analysis of sickness absence among employees of four NHS trusts. Occup Environ Med 1999;56(10):702-8.

[5] Wise J. Audit finds large variations in NHS staff sick days. BMJ 2011;342.

[6] Dame Carol Black. Working for a Healthier Tomorrow, Crown Copyright, The Stationary Office, Available from: www.workingforhealth.gov.uk. 2008

[7] Black DC, Frost D. Health at work - an independent review of sickness absence, The Stationary Office, Norwich, Availabel from: http://www.dwp.gov.uk/policy/welfarereform/sickness-absence-review/. Norwich: 2011.

[8] CIPD. Absence Management. A survey of Policy and Practice. Annual Survey Report 2005.

[9] Allebeck P, Mastekaasa A. Chapter 3. Causes of sickness absence: research approaches and explanatory models. Scand J Public Health 2004;32(63 suppl):36-43.

[10] MacEachen E, Clarke J, Franche R-L, Irvin E, Workplacebased Return Work G. Systematic review of the qualitative literature on return to work after injury. Scand J Work Environ Health 2006;32(4):257-69.

[11] Pompeii LA, Lipscomb HJ, Dement JM. Predictors of lost time from work among nursing personnel who sought treatment for back pain. Work-a Journal of Prevention Assessment \& Rehabilitation 2010;37(3):285-95.

[12] Roelen CAM, Koopmans PC, Notenbomer A, Groothoff JW. Job satisfaction and short sickness absence due to the common cold. Work-a Journal of Prevention Assessment \& Rehabilitation 2011;39(3):305-13.

[13] Westerlund H, Nyberg A, Bernin P, Hyde M, Oxenstierna G, Jappinen P, et al. Managerial leadership is associated with employee stress, health, and sickness absence independently of the demand-control-support model. Work-a Journal of Prevention Assessment \& Rehabilitation 2010;37(1):71-9.

[14] DWP. Fitness for work: The Government response to "Health at work - an independent review of sickness absence". London: 2013.

[15] Hagberg J, Vaez M, Alexanderson K. Methods for analysing individual changes in sick-leave diagnoses over time. Worka Journal of Prevention Assessment \& Rehabilitation. 2010;36(3):283-93.

[16] Gabbay M, Taylor L, Sheppard L, Hillage J, Bambra C, Ford F, et al. NICE guidance on long-term sickness and incapacity. Brit J Gen Pract 2011;61(584):206-7.

[17] HSE. Health and Safety Executive, Managing sickness absence and return to work, Available from: http://www. hse.gov.uk/sicknessabsence/index.htm. 2011

[18] Preece R. Do first-day absence schemes really work? Personnel Today, Available from: http://www. personneltodaycom/articles/2006/07/01/36629/do-firstday-absence-schemes-really-workhtml. 2006

[19] McCluskey S, Burton AK, Main CJ. The implementation of occupational health guidelines principles for reducing sickness absence due to musculoskeletal disorders. Occup Med 2006;56(4):237-42.

[20] Kant I, Jansen NWH, van Amelsvoort LGPM, van Leusden R, Berkouwer A. Structured early consultation with the occupational physician reduces sickness absence among office workers at high risk for long-term sickness absence: A randomized controlled trial. J Occup Rehabil 2008;18(1): 79-86.

[21] Lexis MAS, Jansen NWH, Huibers MJH, van Amelsvoort LGPM, Berkouwer A, Ton GTA, et al. Prevention of longterm sickness absence and major depression in high-risk employees: A randomised controlled trial. Occup Environ Med 2011;68(6):400-7.

[22] Shiri R, Martimo K-P, Miranda H, Ketola R, Kaila-Kangas $\mathrm{L}$, Liira $\mathrm{H}$, et al. The effect of workplace intervention on pain and sickness absence caused by upper-extremity musculoskeletal disorders. Scand J Work Environ Health 2011;37(2):120-8.

[23] Hoefsmit N, Houkes I, Nijhuis FJN. Intervention Characteristics that Facilitate Return to Work After Sickness Absence: A Systematic Literature Review. J Occup Rehabil 2012;22(4):462-77.

[24] Carroll C, Rick J, Pilgrim H, Cameron J, Hillage J. Workplace involvement improves return to work rates among employees with back pain on long-term sick leave: A systematic review of the effectiveness and cost-effectiveness of interventions. Disabil Rehabil 2010;32(8):607-21.

[25] Anema JR, Steenstra IA, Bongers PM, de Vet HCW, Knol DL, Loisel P, et al. Multidisciplinary rehabilitation for subacute low back pain: Graded activity or workplace intervention or both? A randomized controlled trial. Spine 2007;32(3):291-8.

[26] Greenwood JG, Wolf HJ, Pearson JC, Woon CL, Posey P, Main CF. Early Intervention in low-back disability among coal-miners in West Virginia- Negative findings. J Occup Environ Med 1990;32(10):1047-52.

[27] Verbeek JH, van der Weide WE, van Dijk FJ. Early occupational health management of patients with back pain - A randomized controlled trial. Spine 2002;27(17):1844-50. 
[28] FirstCare. Absence Management- Service Description, FirstCare Ltd, Available from: http://www.firstcare.eu/ firstcare-services/absence-management/servicedescription-2/ 2012 [cited 2013 18/06/2013].

[29] Sabbath EL, Melchior M, Goldberg M, Zins M, Berkman LF. Work and family demands: Predictors of all-cause sickness absence in the GAZEL cohort. Eur J Public Health 2012;22(1):101-6.

[30] Palmer KT, Harris EC, Linaker C, Barker M, Lawrence W, Cooper C, et al. Effectiveness of community- and workplace-based interventions to manage musculoskeletalrelated sickness absence and job loss: A systematic review. Rheumatology 2012;51(2):230-42.

[31] Engel GL. Need for a new medical model - Challenge for biomedicine. Science 1977;196(4286):129-36.

[32] Jette AM. Toward a common language for function, disability, and health. Phys Ther 2006;86(5):726-34.

[33] Smedley J, Harris EC, Cox V, Ntani G, Coggon D. Evaluation of a case management service to reduce sickness absence. Occup Med 2013;63(2):89-95.

[34] Hanson M, Murray K, Wu O. Evaluation of OHSxtra, a pilot occupational health case management programme within NHS Fife and NHS Lanarkshire, Available from: http://www.worksout.co.uk/cms/wp-content/ uploads/2009/01/Evaluation-of-OHSxtra.pdf 2007.

[35] Healthy Working Lives. A plan for action, Scottish Executive, Edinburgh, Available from: http://www.scotland. gov.uk/Publications/2004/08/hwls/0. 2005

[36] Health Works. A review of the Scottish Government's Healthy Working Lives Strategy, The Scottish Government, Edinburgh, Available from: http://www.scotland.gov. uk/Publications/2009/12/11095000/0. Edinburgh: 2009.

[37] Reetoo N, Burrows J, Macdonald E. Managing sickenss absence and return to work. Health and Safety Executive (2009), 1-162. Available from: www.hse.gov.uk/research/ rrpdf/rr690.pdf, 2009

[38] DWP. Sickness Absence Review; Available from: http://www.dwp.gov.uk/policy/welfare-reform/sicknessabsence-review/ 2011

[39] ONS. Sickness Absence in the Labour Market, April 2012, Office for National Statistics, Available from: http://www. ons.gov.uk/ons/dcp171776_265016.pdf. 2012.

[40] ISD. Information Services Division, NHS National Services, Sickness Absence, Available from: http://www. isdscotland.org/Health-Topics/Workforce/Publications/ data-tables.asp; Pg. 7, 2010.

[41] The Scottish Government. ANNEX A, 2008/09 HEAT targets. Available from: http://www.scotland.gov.uk/ Publications/2007/12/11103453/6 2007 [07/10/2011].

[42] The Scottish Government. NHS Scotland Efficiency and Productivity: Framework for SR10 - 2011-2015, Available from: http://www.scotland.gov.uk/Resource/ 0039/00398705.pdf. Edinburgh: 2011.

[43] Anema JR, Cuelenaere B, van der Beek AJ, Knol DL, de Vet $\mathrm{HCW}$, van Mechelen W. The effectiveness of ergonomic interventions on return-to-work after low back pain; a prospective two year cohort study in six countries on low back pain patients sicklisted for 3-4 months. Occup Environ Med 2004;61(4):289-94.

[44] Briand C, Durand M-J, St-Arnaud L, Corbiere M. How well do return-to-work interventions for musculoskeletal conditions address the multicausality of work disability? J Occup Rehabil 2008;18(2):207-17.

[45] Franche RL, Baril R, Shaw W, Nicholas M, Loisel P. Workplace-based return-to-work interventions: Optimizing the role of stakeholders in implementation and research. J Occup Rehabil 2005;15(4):525-42.

[46] Franche RL, Cullen K, Clarke J, Irvin E, Sinclair S, Frank J, et al. Workplace-based return-to-work interventions: A systematic review of the quantitative literature. J Occup Rehabil 2005;15(4):607-31.

[47] Demou E, Gibson I, Macdonald EB. Identification of the factors associated with outcomes in a Condition Management Programme. BMC Public Health. 2012;12.

[48] Salus. Occupational Health, Safety \& return to Work Services. Available from: http://www.salus.co.uk/Pages/ default.aspx 2011 [16/10/2011]

[49] Arnetz BB, Sjogren B, Rydehn B, Meisel R. Early workplace intervention for employees with musculoskeletalrelated absenteeism: A prospective controlled intervention study. J Occup Environ Med 2003;45(5):499-506.

[50] Jensen IB, Bergstrom G, Ljungquist T, Bodin L. A 3-year follow-up of a multidisciplinary rehabilitation programme for back and neck pain. Pain 2005;115(3):273-83.

[51] Jensen IB, Bergstrom G, Ljungquist T, Bodin L, Nygren AL. A randomized controlled component analysis of a behavioral medicine rehabilitation program for chronic spinal pain: Are the effects dependent on gender? Pain 2001;91(12):65-78.

[52] Karjalainen K, Malmivaara A, Mutanen P, Roine R, Hurri $\mathrm{H}$, Pohjolainen T. Mini-intervention for subacute low back pain - Two-year follow-up and modifiers of effectiveness. Spine 2004;29(10):1069-76.

[53] Loisel P, Lemaire J, Poitras S, Durand MJ, Champagne F, Stock S, et al. Cost-benefit and cost-effectiveness analysis of a disability prevention model for back pain management: A six year follow up study. Occup Environ Med 2002;59(12):807-15.

[54] de Boer A, van Beek JC, Durinck J, Verbeek J, van Dijk FJH. An occupational health intervention programme for workers at risk for early retirement; a randomised controlled trial. Occup Environ Med 2004;61(11):924-9.

[55] Fleten N, Johnsen R. Reducing sick leave by minimal postal intervention: A randomised, controlled intervention study. Occup Environ Med 2006;63(10):676-82.

[56] Taimela S, Laara E, Malmivaara A, Tiekso J, Sintonen H, Justen S, et al. Self-reported health problems and sickness absence in different age groups predominantly engaged in physical work. Occup Environ Med 2007;64(11):739-46.

[57] IOM. SART: Sickness Absence Recording Tool. http:// www.iom-world.org/sicknessabsence/. 2014.

[58] Brown J, Mackay D, Demou E, Craig J, Macdonald EB. Reducing sickness absence in Scotland - applying the lessons from a pilot NHS intervention. Final Report. Available from: http://www.gla.ac.uk/media/media 289315_en.pdf. Glasgow: 2013.

[59] Soderberg E, Vimarlund V, Alexanderson K. Experiences of professionals participating in inter-organisational cooperation aimed at promoting clients' return to work. Work-a Journal of Prevention Assessment \& Rehabilitation 2010;35(2):143-51.

[60] NHS Scotland. NHS Scotland Staff Opinion Survey 2008. Highlights report for: NHS Lanarkshire, Available from: http://www.scotland.gov.uk/Resource/Doc/924/0076459. pdf. 2008.

[61] Vonk Noordegraaf A, Huirne J, Brolmann H, Emanuel M, van Kesteren P, Kleiverda G, et al. Effectiveness of a multidisciplinary care program on recovery and return to work of patients after gynaecological surgery; design of a randomized controlled trial. BMC Health Serv Res 2012;12(1):29. 
[62] PriceWaterHouseCoopers. Building the case for wellness, Available from: http://www.dwp.gov.uk/docs/hwwb-dwpwellness-report-public.pdf. 2008.

[63] van der Klink JJL, Blonk RWB, Schene AH, van Dijk FJH. Reducing long term sickness absence by an activating intervention in adjustment disorders: A cluster randomised controlled design. Occup Environ Med 2003;60(6):429-37.

[64] Gorman E, Yu S, Alamgir H. When healthcare workers get sick: Exploring sickness absenteeism in British Columbia, Canada. Work-a Journal of Prevention Assessment \& Rehabilitation 2010;35(2):117-23.
[65] Wilford J, McMahon AD, Peters J, Pickvance S, Jackson A, Blank L, et al. Predicting job loss in those off sick. Occup Med 2008;58(2):99-106.

[66] Tompa E, de Oliveira C, Dolinschi R, Irvin E. A systematic review of disability management interventions with economic evaluations. J Occup Rehabil 2008;18(1):16-26.

[67] Brown J, Mackay D, Demou E, Craig J FJ, E. M. The EASY (Early Access to Support for You) sickness absence service: A four year evaluation of the impact on absenteeism. Scand J Work Environ Health 2015;41(2):204-15. 